FRANCIELLI HONORATO ALVES

\title{
O EXERCÍCIO DA COMPETÊNCIA TRIBUTÁRIA MUNICIPAL NA DELIMITAÇÃO DA BASE DE CÁLCULO DO IMPOSTO SOBRE SERVIÇOS
}

\author{
Dissertação de Mestrado \\ Orientador: Professor Associado Dr. Paulo Ayres Barreto
}

\author{
UNIVERSIDADE DE SÃO PAULO \\ FACULDADE DE DIREITO \\ SÃO PAULO-SP \\ 2016
}

Versão corrigida em 05 de julho de 2016. A versão original, em formato eletrônico (PDF), encontra-se disponível na CPG da Unidade. 


\section{RESUMO}

ALVES, Francielli Honorato. O Exercício da Competência Tributária Municipal na Delimitação da Base de Cálculo do Imposto sobre Serviços. 2016. 322 f. Mestrado Faculdade de Direito, Universidade de São Paulo, São Paulo, 2016.

A Constituição Federal de 1988 conferiu aos Municípios e ao Distrito Federal a competência para instituir o imposto sobre serviços de qualquer natureza definidos em lei complementar, com exceção dos serviços de transporte interestadual e intermunicipal e dos serviços de comunicação, que são tributados pelos Estados por meio do ICMS. Um dos pontos principais do exercício daquela competência está na delimitação da base de cálculo do ISS, por se tratar do elemento que indicará o montante da riqueza que o contribuinte obteve com a prestação do serviço e sobre o qual o ISS será calculado. É necessário, então, que a base de cálculo definida na lei municipal para a cobrança do ISS tenha estreita relação com o fato jurídico "prestar serviço de qualquer natureza", pois é somente a riqueza decorrente dessa materialidade que poderá ser atingida pelo ISS. Sendo assim, caso um Município preveja, em lei própria, que os valores que não foram recebidos pelo prestador como remuneração pelo serviço executado em favor do tomador também devem compor a base de cálculo do ISS, a cobrança desse imposto que se baseie nessa lei será inconstitucional, pois atingirá valores que não revelam capacidade contributiva do prestador do serviço. Considerando-se que a Lei Complementar n. ${ }^{\circ} 116 / 2003$, ao exercer a função de lei complementar nacional prescritora de normas gerais em matéria de cobrança de ISS, estabelece que a sua base de cálculo deve ser o "preço do serviço", torna-se necessário verificar quais são os limites semânticos que podem ser atribuídos a essa expressão para que o ISS não seja calculado sobre valores que não representem receita decorrente da prestação de serviço. Para tal análise, primeiramente serão apresentados os critérios que compõem a regra-matriz de incidência do ISS, de tal forma que seja possível demonstrar a relação intrínseca que cada um deles estabelece com a materialidade tributável por meio desse imposto. Relação essa que se destaca no estudo da base de cálculo como critério quantitativo daquela regra-matriz, posto que deve compreender apenas os valores recebidos pelo prestador como remuneração pelo serviço prestado. E para diferenciar esses valores daqueles que são recebidos pelo prestador do serviço do seu tomador como reembolso de despesas, serão propostos alguns critérios objetivos que devem ser aplicados na análise de cada uma das despesas envolvidas em uma prestação do serviço para que se determinem se os valores que serão empregados no seu custeio devem ou não compor a base de cálculo do ISS. Além disso, também serão propostos critérios para diferenciar os valores recebidos pelo prestador que são incorporados ao seu patrimônio daqueles que apenas transitam temporariamente por ele e identificar quais deles sofrerão a incidência do ISS. Por fim, será também analisada a necessidade de prescrição de critérios para o rateio do preço cobrado pela execução concomitante de uma prestação de serviço em estabelecimentos localizados em Municípios diferentes, de tal forma que todos esses Municípios possam definir uma base de cálculo constitucional para a apuração do ISS que cada um tem competência para cobrar sobre esse fato jurídico tributário.

Palavras-chave: Competência tributária. Regra-matriz de incidência tributária. Imposto sobre Serviços. Prestação de Serviço. Base de Cálculo. Preço do Serviço. Ingresso. Receita. Reembolso. Tributação Municipal. 


\begin{abstract}
ALVES, Francielli Honorato. The Competence of Municipalities in Assessing the Tax Base of Tax on Services. 2016. 322 f. Master of Law - Faculty of Law, University of São Paulo, São Paulo, 2016.
\end{abstract}

The Federal Constitution of 1988 attributed to municipalities and the Federal District the competence to institute tax on services of any nature (ISS) as defined in a supplementary law, with exception to interstate and intermunicipal transportation services and services of communication, taxed by the States ICMS. One of the main points of municipalities' competence refers to the assessment of the ISS tax base, by the designation of which value obtained by the taxpayer through the service rendered is subjected to taxation. The tax base defined by the municipal law to charge the ISS should be strictly related to the legal fact of providing service of any nature. Only the value obtained through this materiality is subjected to the ISS. In case a particular municipal legislation anticipates the addition to the ISS tax base of values received by the provider other than the compensation for the service rendered in favor of a client, the charging of the tax based on this law will be unconstitutional, since it deals with values over the taxpayers' contributive capacity. While performing the function of prescribing national general norms related to ISS charging, Supplementary Law 116/2003 establishes that the tax base should be the "price of service." It becomes necessary to verify the semantic limits that may be attributed to the expression "price of service" to avoid the calculation of ISS on values that do not represent the service compensation. For such analysis, this thesis presents, first, the criteria that form the rule array of ISS incidence, demonstrating the intrinsic relation of each one of the criterion with the taxable materiality. This relation stands out in the study of the tax base as a quantitative criterion of the rule array of ISS incidence, since it should encompass only the values received by the provider as compensation for the service rendered. To differentiate these values from those received by the service provider from the client as reimbursement of expenses, this thesis proposes objective criteria to analyze each expenditure involved in a service provision, in order to determine whether the values applied to its costing should form the ISS tax base. This thesis also proposes criteria to differentiate values received that are definitely incorporated to the provider's patrimony from those that are temporary. These criteria also identify which of these values could be subjected to the ISS. Finally, this thesis analyses the prescription of criteria to the assessment of the price charged for service simultaneously provided at facilities located at different municipalities, making it possible for all these municipalities to define a constitutional tax base to assess the ISS each one has the competence to charge.

Keywords: Taxing Power. Rule array of tax incidence. Service Tax. Service. Tax Base. Price of Service. Inflow. Income. Repayment. Municipal Taxation. 


\section{Introdução}

A Constituição Federal de 1988 alçou o fato jurídico "prestar serviços" como materialidade reveladora de riqueza produzida pela pessoa física ou jurídica que o realiza e que poderia ser alcançada pela cobrança de impostos. Cobrança que deveria ser feita no limite da capacidade contributiva de cada prestador de serviço e atuaria como meio de o Estado garantir recursos para a manutenção financeira da sua estrutura administrativa e da prestação de serviços públicos.

Diante da grande quantidade e diversidade de fatos que poderiam vir a ser considerados como prestação de serviço para fins dessa tributação, o constituinte originário optou por repartir a competência para essa tributação entre os Estados e os Municípios. Utilizou-se, então, do art. 155, inciso II do texto constitucional, para atribuir aos Estados a competência para cobrar imposto sobre a prestação de serviço de transporte interestadual ou intermunicipal e sobre a prestação de serviço de comunicação. Essa competência é exercida por meio da cobrança do Imposto sobre Circulação de Mercadoria e Serviços (ICMS). Aos Municípios, coube a competência de tributar todas as demais prestações de serviço que não fossem tributadas pelos Estados e que estivessem devidamente definidas em lei complementar, conforme prescreve o art. 156, inciso III da Constituição. Por fim, ao Distrito Federal foram atribuídas ambas as competências tributárias.

O presente trabalho concentra-se no estudo da competência tributária que foi atribuída aos Municípios e ao Distrito Federal para a instituição e a cobrança do chamado "Imposto sobre Serviço" (ISS) ou "Imposto sobre Serviço de Qualquer Natureza" (ISSQN)1. De forma mais específica, dedica-se principalmente à proposta de novos critérios jurídicos, construídos com base na análise pragmática de diferentes tipos de prestações de serviço, que possam ser empregados para identificar quais dos valores recebidos pelo prestador do seu tomador caracterizam-se como riqueza decorrente daquela materialidade e, por isso, devem ser tributados por meio do ISS, diferenciando-os dos demais valores que, sendo recebidos como meros ingressos ou como reembolso de despesas, não podem ser atingidos por esse imposto.

\footnotetext{
${ }^{1}$ Apesar de essas duas expressões serem igualmente válidas, optou-se por empregar, neste trabalho, apenas a expressão "Imposto sobre Serviços" ou a sigla "ISS" para fazer referência a esse imposto municipal.
} 
Considerando-se que, atualmente, existem 5.570 Municípios no território brasileiro, há uma grande quantidade de entes federados competentes para tributar as prestações de serviço de qualquer natureza, o que demonstra a importância de um estudo que se dedique, inicialmente, aos detalhes que caracterizam determinado fato jurídico como "prestação de serviço" tributável por meio desse imposto. Essa identificação mais precisa poderá evitar que diferentes Municípios prevejam, em suas respectivas legislações, fatos que não tenham a natureza de prestação de serviço, cercando o alargamento inconstitucional da competência tributária atribuída aos Municípios.

Além disso, também se mostra necessária a busca pela definição da grandeza capaz de medir a extensão da materialidade "prestar serviços de qualquer natureza", de tal forma que os prestadores de serviço sejam tributados por qualquer um dos Municípios brasileiros apenas com base naquela riqueza que produziram e da qual passaram a ser titulares em razão da realização de uma prestação de serviço em benefício de um tomador. Isso porque, caso estabeleça como base de cálculo para a cobrança do ISS um elemento que atinja valores superiores à riqueza obtida pelo prestador de serviço em razão da atividade realizada, além de eleger base de cálculo incompatível com o fato jurídico a ser tributado, o legislador municipal estará também prescrevendo o exercício de uma tributação fora dos limites da competência constitucional atribuída ao ente federado que ele representa. Sendo assim, torna-se necessário o desenvolvimento de um estudo que identifique qual a grandeza que, estando adequada à materialidade prevista no art. 156, inciso III da Constituição Federal como tributável por meio do ISS, pode ser eleita pelos legisladores municipais como base de cálculo para uma cobrança constitucional desse imposto.

Nesse contexto, o desenvolvimento do presente trabalho de dissertação de mestrado não pode deixar de considerar as prescrições postas pela Lei Complementar n. ${ }^{\circ}$ 116/2003 como normas gerais a serem seguidas obrigatoriamente por todos os Municípios e pelo Distrito Federal no exercício de sua competência para tributar as prestações de serviço de qualquer natureza. Entre essas normas, está aquela que estabelece o "preço do serviço" como base de cálculo do ISS. É possível afirmar, de antemão, que essa legislação complementar não cumpre integralmente a função que lhe foi atribuída pelo art. 146, inciso III do texto constitucional, tendo em vista que não elenca limites precisos para que se possa estabelecer com segurança quais valores envolvidos em uma prestação de serviço devem ou não compor o que se nomeia de "preço do serviço". Considerando, então, os enunciados prescritivos de caráter nacional que tratam sobre a cobrança do Imposto sobre Serviços no ordenamento jurídico brasileiro atual, este trabalho de dissertação de mestrado tem como objetivo verificar 
quais os limites que, de acordo com a Constituição Federal, devem ser seguidos pelos Municípios e pelo Distrito Federal na delimitação dos valores que devem ou não integrar a expressão "preço do serviço", empregada como base de cálculo do ISS.

Não se pode deixar de considerar, ainda, que uma grande parte das leis municipais atualmente vigentes prescrevem que, para fins de apuração da base de cálculo do ISS, o "preço do serviço" deve ser considerado como a "receita bruta" obtida em razão da prestação do serviço. Por isso, integra também este trabalho a proposta de analisar quais os limites do conceito de "receita", de tal forma que seja possível diferenciar os valores que realmente passaram à titularidade do prestador de serviço em razão da execução do serviço daqueles valores que foram recebidos por ele a título de mero ingresso ou de reembolso de despesas cujo pagamento já tenha sido antecipado por ele. Como resultado dessa análise, pretende-se construir critérios jurídicos objetivos que permitam identificar quais valores recebidos pelo prestador de serviço do seu tomador adequam-se ou não ao conceito de receita e, consequentemente, podem ou não ser incluídos na base de cálculo do Imposto sobre Serviço. Essa identificação se faz necessária para que a cobrança desse imposto seja feita dentro dos limites da competência tributária dos entes federados envolvidos. Esses limites seriam extrapolados caso a cobrança do ISS atingisse também os valores caracterizados como meros ingressos ou como reembolsos de despesas.

Considerando-se que a dinâmica cada vez maior das atividades econômicas leva a pessoa jurídica prestadora de serviços a montar mais de um estabelecimento para a execução de seus serviços, em territórios de Municípios distintos, também se mostra relevante para este trabalho a realização de uma análise dos efeitos desse tipo de organização empresarial na apuração da base de cálculo do ISS. Essa análise se torna mais saliente quando os estabelecimentos localizados em Municípios diferentes concorrem para a execução de um mesmo serviço, sem que seja possível definir em qual deles é exercida uma atividade meramente administrativa e em qual se realiza a prestação de serviço propriamente dita. Diante dessa realidade e para complementar o presente trabalho, pretende-se verificar se, no ordenamento jurídico atual e, especialmente, na Lei Complementar n. ${ }^{\circ}$ 116/2003, existe a previsão de critérios legais para identificar qual ente federado terá competência para tributar essa prestação de serviço executada concomitantemente nos territórios de mais de um Município. Como consequência, também será necessário verificar se existem critérios legais que prescrevam a forma como deve ser delimitada a parcela do "preço do serviço" cobrado em razão dessa prestação de serviço que poderá ser considerada como base de cálculo do ISS a ser cobrado por cada um desses Município sobre essa mesma prestação de serviço. Por 
fim, caso se constate a inexistência desses critérios, analisar-se-á se as autoridades administrativas, no momento de realização e de revisão do lançamento tributário, assim como as autoridades judiciais, no momento de julgamento do tributo lançado, poderão ou não adotar critérios que, apesar de aparentemente "justos" e objetivos, não estão previstos na legislação vigente para delimitar a base de cálculo aplicada na apuração do ISS incidente sobre o caso concreto.

Para que a execução de todas essas análises seja apresentada de forma lógica e coerente, este trabalho está organizado em duas grandes partes, divididas no total de oito capítulos.

Na primeira parte, são estudados os diferentes elementos que compõem a regramatriz de incidência do Imposto sobre Serviços. Para fundamentar a construção de cada um desses critérios que compõem aquela norma jurídica geral e abstrata de incidência tributária, o primeiro capítulo dessa grande parte é dedicado ao estudo da repartição constitucional de competências tributárias, especialmente no que diz respeito às competências para a cobrança de impostos, atribuídas aos entes federados com base em conceitos jurídicos. O mesmo capítulo trata das funções atribuídas pela Constituição Federal à lei complementar de caráter nacional e do papel desse tipo de instrumento normativo na delimitação da materialidade tributável por meio do ISS.

Os outros quatro capítulos dessa primeira parte são dedicados ao estudo de cada um dos critérios mínimos que compõem a estrutura lógica da regra-matriz de incidência do ISS, cuja função é determinar o cálculo do valor do tributo que será objeto da relação jurídica tributária que será estabelecida entre um Município e o sujeito prestador de serviço, quando verificada, no mundo fático, a ocorrência de uma prestação de serviço descrita como fato imponível tributário na hipótese daquela norma geral. Esse estudo tem como principal fundamento a verificação, no capítulo 2 , de qual é o conceito jurídico atribuído à materialidade "prestar serviço". A partir disso, nos capítulos 3, 4 e 5, são analisadas as relações que os critérios temporal, espacial, pessoal e quantitativo estabelecem com esse critério material da regra-matriz de incidência do ISS, de tal forma que seja possível demonstrar que a identificação de cada um desses critérios decorre necessariamente da concretização da materialidade "prestar serviço".

Maior ênfase é dedicada ao estudo da relação entre a base de cálculo, como critério quantitativo da regra-matriz de incidência do Imposto sobre Serviços, e a materialidade tributável por meio desse imposto. Esse é o tema central da segunda parte desta dissertação, que, por sua vez, está dividida em três grandes capítulos, nos quais são construídos elementos 
para uma melhor definição de uma base de cálculo do ISS, que esteja de acordo com os limites da competência atribuída pela Constituição Federal aos Municípios para a cobrança desse imposto.

O primeiro capítulo dessa segunda parte é dedicado ao estudo da expressão "preço do serviço" como medida da materialidade "prestar serviço". Para tanto, são analisadas as similaridades e as diferenças dos conceitos atribuídos ao signo "preço" pelas Ciências Contábeis e pelo Direito Civil brasileiro, servindo de fundamentação para a identificação dos limites do conceito atribuído à expressão "preço do serviço" pelo Direito Tributário, especialmente para fins de apuração do ISS.

No segundo capítulo, é desenvolvido um estudo da etimologia dos termos "ingresso", "receita" e "reembolso", seguido da análise dos significados atribuídos a cada um deles pela doutrina e pela jurisprudência brasileira atuais. Com esse estudo da etimologia e dos significados, define-se quais desses valores podem ser considerados como base de cálculo do Imposto sobre Serviço e quais não devem sofrer a incidência desse imposto, considerando-se a relação de cada um deles com a produção de riqueza a partir da execução de uma prestação de serviço. A partir disso e ainda nesse capítulo dois, verifica-se se a lei complementar de caráter nacional atualmente vigente define de forma satisfatória a base de cálculo do ISS e se cabe essa definição à lei ordinária municipal, instituidora do ISS em cada Município, como forma de garantir maior segurança jurídica às autoridades fiscais e aos sujeitos passivos desse imposto.

Por fim, no terceiro capítulo dessa segunda parte e último da presente dissertação, surge o componente principal deste trabalho: a proposta de critérios jurídicos objetivos que possam ser utilizados para diferenciar valores recebidos pelo prestador de serviço a título de receitas de serviços, de reembolso de despesas ou de meros ingressos. Esses critérios servem, ao final, para definir quais valores deverão ou não compor a base de cálculo do Imposto sobre Serviços. Para a demonstração da validade de cada um dos critérios propostos, eles são aplicados a situações hipotéticas e também a casos reais de prestações de serviço que foram levadas à apreciação do Conselho Municipal de Tributos da Prefeitura de São Paulo, ao Tribunal de Justiça do Estado de São Paulo e ao Superior Tribunal de Justiça. Em cada uma dessas situações, são classificados os valores identificados como receita, reembolso ou mero ingresso e verifica-se se a base de cálculo do ISS definida nas decisões proferidas por esses órgãos administrativos ou judiciais está ou não de acordo com o texto constitucional.

Para encerrar esse último capítulo, apresenta-se uma análise de algumas hipóteses de realização de uma mesma prestação de serviço em estabelecimentos localizados em 
Municípios diferentes, nos quais se verifica a ocorrência de possíveis conflitos de competência. Essa análise será feita com a distinção entre os casos em que um desses estabelecimentos realiza apenas uma atividade-meio relacionada à atividade-fim para a qual a prestadora de serviço foi contratada e aqueles em que se verifica a execução complementar da atividade-fim em ambos os estabelecimentos. Finaliza-se esse capítulo com uma proposta de soluções para a definição da base de cálculo do Imposto sobre Serviços incidente sobre esse tipo de prestação de serviço que, em conformidade com o Sistema Constitucional Tributário, devem ser aplicadas a esses casos e a relação das soluções propostas com a legislação complementar atual.

Trata-se, portanto, de um trabalho de dissertação de mestrado que tem o objetivo de identificar os limites constitucionais que decorrem da materialidade "prestação de serviço de qualquer natureza" e que devem ser seguidos pelos Municípios e pelo Distrito Federal no exercício da competência que lhes foi atribuída para estabelecer os valores que serão considerados como base para o cálculo do ISS incidente sobre as diferentes prestações de serviço sujeitas à sua cobrança ${ }^{2}$. Pretende-se, assim, que este trabalho possa servir de orientação para os inúmeros entes federados aos quais o art. 156, inciso III da Carta Magna atribuiu a competência para cobrar o Imposto sobre Serviços a respeito de quais os limites que devem seguir na delimitação da base de cálculo do Imposto sobre Serviços, a fim de que a instituição e a cobrança desse imposto sejam sempre realizadas de forma constitucional.

\footnotetext{
${ }^{2}$ A possibilidade de cobrança do ISS em valor fixo, prevista no art. $9^{\circ}$, $^{\circ}{ }^{\circ}$ e $§ 3^{\circ}$ do Decreto-Lei n. ${ }^{\circ} 406 / 1968$, não será abordada nesta dissertação de mestrado. A intrínseca relação existente entre a materialidade e a base de cálculo da regra-matriz de incidência do Imposto sobre Serviços, premissa principal que guia a construção deste trabalho, não é relevante para o cálculo de impostos cobrados em valores fixos, o que justifica a dedicação exclusiva ao estudo da cobrança do ISS em valor variável.
} 


\section{CONCLUSÕES}

\section{Parte I - A regra-matriz de incidência do Imposto sobre Serviços}

1. A repartição constitucional de competências tributárias foi realizada com a prescrição das únicas espécies tributárias que podem ser instituídas e cobradas por cada ente que compõe a República Federativa do Brasil.

1.1. Em relação à espécie "imposto", o texto constitucional elencou expressamente as únicas materialidades indicadoras de riqueza do contribuinte que podem ser atingidas pela sua cobrança, distribuindo cada uma delas de forma privativa à União, aos Estados, ao Distrito Federal e aos Municípios (com a ressalva apenas da competência residual da União para instituir impostos sobre outras possíveis materialidades, desde que o faça por meio de lei complementar).

1.2. Se um ente federado prever em lei própria a cobrança de um imposto sobre materialidade que não lhe foi atribuída, estará instituindo tributo inconstitucional. Da mesma forma, ainda que institua o imposto sobre materialidade que está na sua competência, se a base de cálculo eleita para a sua apuração não tiver relação com aquela materialidade, essa cobrança será inconstitucional.

2. O conceito jurídico adotado pelo constituinte originário na atribuição da competência para tributar determinada materialidade a um ente federado deve ser seguido por ele na instituição, em lei própria, da cobrança desse imposto.

2.1. Assumiu-se o entendimento de que o constituinte de 1988 , por não ter feito nenhuma ressalva expressa sobre o conceito de cada instituto jurídico utilizado na repartição de competências tributárias, adotou os conceitos jurídicos vigentes no ordenamento jurídico brasileiro na época da promulgação da Constituição Federal.

2.2. O constituinte de 1988, ao atribuir aos Municípios e ao Distrito Federal a competência para tributar "serviços de qualquer natureza" (art. 156, inciso III), não prescreveu expressamente se o verbo ao qual deveria ser ligado esse complemento para identificar o fato jurídico tributável por meio do ISS deveria ser o verbo "prestar" ou o verbo “tomar”. Contudo, é possível afirmar que somente o prestador do serviço gera riqueza nova 
com a execução de um contrato de prestação de serviço, sendo o sujeito que revela capacidade contributiva passível de ser tributada por meio desse imposto.

3. Em relação ao Imposto sobre Serviços, o texto constitucional prescreve expressamente a necessidade de definição dos limites do conceito de "serviço de qualquer natureza" em lei complementar de caráter nacional. Nessa definição, o legislador complementar deve seguir o conceito atribuído à prestação de serviço pelas regras do Direito Privado vigentes no momento da elaboração e da publicação do texto constitucional.

3.1. É possível afirmar que o constituinte de 1988 adotou o mesmo significado jurídico do Código Civil de 1916, ao prever o termo "serviço" como materialidade indicativa de riqueza tributável pelos Municípios por meio do ISS. Nesse caso, o termo "serviço" pressupõe um contrato bilateral e oneroso, realizado entre partes independentes, que tenha como objeto uma obrigação de fazer a ser realizada por uma parte em benefício da outra e que será compensada com o pagamento de certa quantia em dinheiro previamente estipulada.

3.2. O Código Civil de 2002 manteve as características da bilateralidade, da onerosidade, da consensualidade, da comutatividade e da falta de formalidade do contrato de prestação de serviço. Também manteve a estipulação do preço do serviço como elemento essencial do contrato, que pode não ser fixado em dinheiro, o que não impede a incidência do ISS sobre a prestação de serviço realizada. Todavia, não há que se falar na tributação de prestação de serviço realizada de forma gratuita, tendo em vista a inexistência de riqueza envolvida no fato jurídico ocorrido.

3.3. Não se enquadram no conceito civil de "prestação de serviço" as prestações de serviços sujeitas às leis trabalhistas, reguladas por legislação própria, por haver subordinação entre as partes. Além disso, falta a esse tipo de serviço a característica da bilateralidade do contrato de prestação de serviço, tendo em vista que o trabalhador age em nome da empresa empregadora nas ações que realiza em razão do contrato de trabalho.

3.4. Também os contratos de prestação de serviços públicos não estão sujeitos à incidência de ISS, pois são realizados de acordo com regras de caráter administrativo e no âmbito do direito público.

4. No exercício da função de definir os fatos jurídicos que podem ser tributados por meio do ISS, o legislador complementar nacional não está autorizado a incluir, nesse possível campo de incidência do ISS, fato jurídico que não corresponda àquele conceito de 
"prestação de serviço" prescrito pelo Direito Civil, pois, se o fizer, estará ampliando indevidamente a competência tributária atribuída aos Municípios pela Constituição.

4.1. Atualmente, a materialidade tributável por meio do ISS é definida de forma denotativa pela Lei Complementar n. ${ }^{\circ}$ 116/2003, que elenca, em uma lista anexa ao seu texto, as únicas atividades que podem ser consideradas como prestação de serviço para fins da cobrança desse imposto municipal.

4.2. A definição denotativa em forma de lista, apesar de prejudicar a autonomia do legislador municipal, que fica impedido de eleger, como hipótese de incidência do ISS, fato jurídico não previsto naquela lista, garante a segurança jurídica dos potenciais contribuintes desse imposto, ao delimitar taxativamente o campo máximo de incidência do ISS que pode ser adotado por todos os Municípios brasileiros.

5. Para que a ocorrência de uma das atividades previstas na lista anexa à Lei Complementar n. ${ }^{\circ}$ 116/2003 possa ser tratada como prestação de serviço tributável por meio do ISS, é necessário que apresente as seguintes características: (i) a execução de uma obrigação de fazer (realização de um esforço humano, físico ou intelectual) que resulte em benefício material ou imaterial a terceira pessoa; (ii) a decorrência de um contrato bilateral, em que um sujeito presta serviço a outro, posto que a prestação de serviço em benefício próprio não revela riqueza tributável; (iii) a existência de um conteúdo econômico atrelado ao esforço realizado pelo prestador, independentemente da obtenção de lucro ou do recebimento do preço do serviço cobrado; (iv) a habitualidade do exercício da atividade pelo prestador do serviço; (v) a celebração de contrato, ainda que informal, de acordo com as regras do Direito Privado; (vi) a inexistência de subordinação entre prestador e tomador de serviço; e (vii) a ocorrência efetiva da prestação do serviço, não bastando a mera celebração daquele contrato.

6. Se a materialidade atribuída pelo texto constitucional aos Municípios para ser tributada por meio do ISS é o fato jurídico "prestar serviço de qualquer natureza", todos os critérios que compõem o antecedente e o consequente da regra-matriz de incidência do ISS também devem estar diretamente relacionados a essa materialidade, a fim de garantir a constitucionalidade da cobrança desse imposto. 
7. O critério temporal de um tributo identifica o momento em que deve ocorrer o fato jurídico tributário para que nasça a obrigação tributária para o sujeito que o praticou. Por isso, deve estar intimamente relacionado ao critério material desse tributo.

7.1. No caso do Imposto sobre Serviços, o critério temporal da sua regra-matriz de incidência deve ser o momento em que o prestador de serviço já tenha finalizado a prestação do serviço de forma total ou parcial. Não pode ser momento anterior ao início da execução do serviço, pois o ISS não incide sobre meros contratos.

7.2. A legislação ordinária municipal pode prever expressamente o fracionamento da ocorrência desse fato jurídico em diferentes momentos, a depender da complexidade do serviço prestado. Nesse caso, a base de cálculo do ISS incidente em cada momento deve equivaler à parcela da materialidade executada no período correspondente.

8. O critério espacial da regra-matriz de incidência de um tributo tem a função de identificar o local em que deve ser concretizado um fato jurídico para que se instaure a relação jurídica tributária para a cobrança daquele tributo.

8.1. No caso do Imposto sobre Serviços, é no território do Município em que o serviço for prestado que se considera ocorrida a materialidade tributável por meio desse imposto, independentemente do local onde esse prestador tenha um estabelecimento ou do local onde está o tomador do serviço.

8.2. Quando os elementos envolvidos em uma mesma prestação de serviço (prestador, tomador, local de execução do serviço) encontram-se em territórios de Municípios distintos, sempre é necessário verificar, em cada caso concreto, o local onde o prestador executa a atividade-fim contratada, pois é nele que se considera ocorrido o fato jurídico tributável por meio do ISS, independentemente de existir outra atividade-meio executada em outro Município.

8.3. Os possíveis conflitos de competência que podem surgir na cobrança de ISS quando os elementos de uma prestação de serviço estão envolvidos em territórios de Municípios diferentes são dirimidos pelas regras prescritas nos arts. $3^{\circ}$ e $4^{\circ}$ da Lei Complementar n. ${ }^{\circ} 116 / 2003$.

8.4. Como regra geral, considera-se ocorrida a prestação do serviço no ponto geográfico onde está o estabelecimento prestador do serviço, definido como o local onde o prestador reúne, de forma permanente ou temporária, a mão-de-obra, os equipamentos e os instrumentos necessários para a execução desse serviço. Trata-se, portanto, do local onde a prestação de serviço, em regra, é praticada. 
8.5. No caso das atividades que exigem o deslocamento de todos esses elementos para o local onde o serviço precisa ser executado, é nesse ponto geográfico que se considera concretizada a materialidade tributável por meio do ISS. Grande parte dessas situações está prevista nos incisos I a XXII do art. $3^{\circ}$ da mesma Lei Complementar.

8.6. Destaca-se o entendimento de que a verificação do local em que a prestação de serviço é efetivamente concretizada deve ser feita em relação a toda e qualquer atividade tributável por meio do ISS, esteja ela ou não nessa lista de exceção do art. $3^{\circ}$ da LC n..$^{\circ}$ 116/2003, pois somente esse local é capaz de definir a competência de um Município para a cobrança de ISS sobre esse fato.

8.7. Aplica-se, assim, o princípio da territorialidade, que determina que um ente federado somente tem competência para tributar determinado fato jurídico se a ocorrência estiver relacionada ao seu território.

8.8. Como consequência, somente o valor da riqueza produzida no território do Município com a execução da prestação de serviço poderá ser considerado como base para o cálculo do valor do ISS incidente sobre a atividade.

9. Se a materialidade que pode ser tributada por meio do ISS é o fato jurídico "prestar serviço" e não o fato de "tomar serviço", apenas o sujeito que realiza essa atividade é que pode ser eleito pelo legislador municipal como contribuinte do ISS.

9.1. O vínculo jurídico existente entre o tomador do serviço e a prestação do serviço permite apenas que ele seja eleito pelo legislador municipal como sujeito "responsável" por reter o valor do ISS, no momento de realizar o pagamento do preço do serviço ao seu prestador, e por repassá-lo aos cofres municipais.

10. Como um dos elementos que compõem o critério quantitativo da regra-matriz de incidência de um tributo, a alíquota pode corresponder a um número percentual ou inteiro, cuja função é indicar o quanto do total da riqueza considerada como base de cálculo de um tributo corresponderá ao valor a ser pago pelo seu sujeito passivo.

10.1. A alíquota é o único dos elementos que compõem a regra-matriz de incidência do ISS que não está diretamente relacionado à materialidade "prestar serviço". O valor máximo de $5 \%$ (cinco por cento) e mínimo de $2 \%$ (dois por cento) que hoje devem ser seguidos pelos Municípios na instituição e cobrança do ISS foram fixados de forma arbitrária no art. $8^{\circ}$, inciso II da Lei Complementar n. ${ }^{\circ} 116 / 2003$ e no art. 88, inciso I do Ato das disposições Constitucionais Transitórias. 
11. A base de cálculo é a grandeza que representa a medida da riqueza manifesta pelo fato jurídico tributário ocorrido no mundo real.

11.1. Se a prestação de serviço de qualquer natureza foi eleita pelo constituinte como fato jurídico indicador de capacidade contributiva do sujeito que a realiza, a base de cálculo do imposto incidente sobre esse fato necessariamente deve ser a expressão da riqueza decorrente dessa materialidade e elemento capaz de medir a sua extensão.

11.2. O legislador complementar nacional elegeu o "preço do serviço" como grandeza a ser considerada como base de cálculo do ISS. Ainda que esse elemento seja capaz de medir a riqueza produzida com a prestação do serviço, a sua previsão genérica no art. $7^{\circ}$, caput da Lei Complementar n. ${ }^{\circ}$ 116/2003 não é capaz de delimitar, de forma clara e objetiva, quais dos valores recebidos pelo prestador de serviços do seu tomador podem ou não ser considerados como "preço do serviço" e, como tal, devem compor a base de cálculo do ISS.

11.3. Para atender ao princípio da capacidade contributiva, que impõe a busca por elementos que evidenciem a força econômica do seu contribuinte e a sua possibilidade de suportar determinada carga tributária, os Municípios brasileiros somente poderão considerar como base de cálculo do ISS os valores recebidos pelo prestador do serviço como forma de remuneração pelo serviço prestado.

11.4. Apenas os valores recebidos como receita de prestação de serviço mensuram a capacidade econômica que o prestador do serviço tem em razão do exercício da sua atividade. Qualquer outro tipo de valor que seja incluído na base de cálculo do ISS levará a uma tributação mais gravosa que aquela que poderá ser suportada por sua capacidade contributiva, o que a tornará inconstitucional.

\section{Parte II - A base de cálculo do Imposto sobre Serviços}

1. A Constituição Federal atribuiu à lei complementar nacional a função de estabelecer normas gerais relacionadas à cobrança de tributos, entre as quais está a definição da base de cálculo dos impostos.

1.1. A Lei Complementar . $^{\circ} 116 / 2003$, no caput do seu art. $7^{\circ}$, prescreve que a base de cálculo do Imposto sobre Serviços é o “preço do serviço”. Essa prescrição não delimita de forma objetiva quais os valores que o prestador do serviço recebe do seu tomador que se caracterizam ou não como preço do serviço. 
1.2. A única ressalva feita por aquela lei complementar em relação a essa matéria diz respeito à apuração da base de cálculo do ISS incidente sobre os serviços de construção civil, prescrevendo que esse imposto não deve incidir sobre o valor que o prestador de serviço recebe do tomador como reembolso pelos materiais adquiridos e empregados na obra realizada.

2. A delimitação da base de cálculo do ISS pressupõe a definição do que se entende por "preço do serviço".

2.1. Para as Ciências Contábeis, "preço do serviço" é a quantia que o prestador de um serviço cobra do seu tomador, que seja capaz de cobrir o custo de execução desse serviço, além dos gastos administrativos, comerciais e financeiros decorrentes do exercício dessa atividade econômica e que também possibilite a obtenção de certo lucro.

2.2. Por sua vez, o Código Civil brasileiro utiliza o termo "retribuição" para se referir ao "preço do serviço" cobrado pelo prestador do seu tomador. O termo "remuneração" também é utilizado pela doutrina pátria para se referir a essa contraprestação que o prestador do serviço tem direito de exigir do seu tomador como retribuição pela atividade executada em seu benefício.

2.3. Para fins da análise da cobrança do ISS, a doutrina tributária brasileira considera a expressão "preço do serviço" como equivalente ao valor recebido pelo prestador de serviço como contraprestação pela obrigação de fazer que realizou em benefício de um sujeito, sob o regime de direito privado e sem qualquer subordinação.

2.4. A eleição do preço do serviço como base de cálculo do ISS está de acordo com os limites impostos pela Constituição Federal à cobrança desse imposto, pois se trata de valor capaz de medir a riqueza decorrente da materialidade "prestar serviço".

3. Para melhor delimitar a base de cálculo do ISS, é necessário diferenciar quais dos valores recebidos pelo prestador são receita de serviço, quais são reembolsos de despesas e quais devem ser considerados como meros ingressos. Apenas os primeiros correspondem ao preço do serviço e podem ser atingidos pela cobrança daquele imposto.

3.1. Por "ingresso" deve-se considerar todos os valores que entram no caixa do prestador de serviços em decorrência de pagamento feito pelo seu tomador.

3.2. Já os valores que entram no caixa da pessoa física ou jurídica como remuneração pelo serviço prestado por ela e que passam a fazer parte do seu patrimônio devem ser considerados como "receita" de prestação de serviço. 
3.3. Por fim, são considerados como "reembolso" de despesa os valores que o prestador de serviço recebe para recompor o seu patrimônio da forma como ele existia antes de o prestador ser obrigado a custear, no curso da execução do serviço, determinadas despesas específicas próprias do tomador.

3.4. Somente os valores recebidos pelo prestador de serviço a título de receita podem ser equiparados à expressão "preço do serviço" para fins de apuração da base de cálculo do ISS. Isso porque apenas esses valores são pagos ao prestador com a finalidade de remunerar a atividade realizada em favor do tomador. Esses são os únicos valores diretamente relacionados à materialidade "prestar serviços", tributável por meio do ISS.

3.5. Não revelam a produção de qualquer riqueza nova pelo prestador de serviços os valores recebidos que já tenham destino certo, seja o de repasse a terceiro titular do direito de recebê-lo, seja o de recomposição de valores específicos pagos antecipadamente pelo prestador, que agia em nome do seu tomador. Por não revelarem capacidade contributiva do prestador, esses valores recebidos por ele não podem ser equiparados à expressão "preço do serviço" para definição da base de cálculo do ISS.

4. O objetivo principal deste trabalho foi verificar quais os limites que, de acordo com a Constituição Federal, devem ser seguidos pelos Municípios e pelo Distrito Federal na delimitação dos valores que devem ou não integrar a expressão "preço do serviço", empregada como base de cálculo do Imposto sobre Serviços.

4.1. Para cumprir esse objetivo, foi proposto inicialmente o critério que diferencia despesas próprias do prestador do serviço de despesas próprias do tomador, que seriam custeadas, respectivamente, por receitas de serviço e por reembolsos de despesas.

4.2. Despesas próprias do prestador do serviço são aquelas que decorrem da atividade-fim para o qual o prestador foi contratado e são remuneradas com o pagamento de receita de prestação de serviço, valor que deve compor a base de cálculo do ISS.

4.3. Por sua vez, as despesas próprias do tomador são aquelas que o prestador tem com a realização de atividades-meio exigidas de forma particular por um tomador do serviço e que não são essenciais para a prestação de serviço principal. O seu valor é pago antecipadamente pelo prestador do serviço, que, posteriormente, é reembolsado pelo tomador com o pagamento de valores que, por não remunerarem a prestação de serviço propriamente dita, não devem fazer parte da base de cálculo do ISS. 
5. A inexistência de prescrição, na legislação complementar nacional, para que valores recebidos pelo prestador de serviços a título de mero ingresso ou de reembolsos de despesas do tomador não sejam incluídos na base de cálculo do ISS não autoriza a incidência desse imposto sobre esses valores, posto que não correspondem a receita de prestação de serviço.

5.1. A legislação municipal não pode incluir, na base de cálculo do ISS, valores que não expressem riqueza decorrente da concretização de uma prestação de serviço, materialidade que o constituinte destacou como tributável por meio daquele imposto.

5.2. Por outro lado, não é obrigatório que a legislação municipal prescreva todos os valores que não serão inclusos na base de cálculo do ISS para que o contribuinte desse imposto tenha direito de recolhê-lo apenas sobre os valores que correspondam ao "preço do serviço", pois esse seu direito já é garantido pela própria Constituição Federal.

6. Ainda para tentar identificar cada um dos tipos de ingressos que possam estar presentes nas diversas prestações de serviço sujeitas à incidência do ISS, foi proposta a utilização de alguns critérios objetivos que permitem diferenciar "receitas de serviço" e "reembolsos de despesas", de tal forma que seja possível definir uma base de cálculo do ISS que atenda aos limites da competência tributária atribuída pela Constituição aos Municípios para a cobrança desse imposto.

6.1. Primeiramente, foram propostos três critérios objetivos para serem aplicados na análise das despesas a serem custeadas por receitas de serviços ou por reembolsos de despesas. Trata-se dos critérios (i) da especificidade da despesa, (ii) da divisibilidade da despesa e (iii) da prescindibilidade da despesa, que devem estar presentes de forma cumulativa em uma despesa para que o valor que se destina ao seu custeio possa ser classificado como mero reembolso.

6.2. Caso um ou mais desses três critérios não possa ser aplicado em relação a uma despesa tida pelo prestador, essa despesa será caracterizada como despesa própria do prestador, que deverá ser custeada com receita de prestação de serviço.

7. O critério da especificidade da despesa identifica as despesas que não estão intrinsecamente relacionadas à natureza da prestação do serviço em questão e, como tais, não são custeadas pela receita obtida com a cobrança do preço do serviço. Seriam específicas as despesas realizadas apenas na prestação de um serviço em benefício de um determinado 
tomador, não se tratando, então, de despesa que o prestador sempre será obrigado a ter para realizar a sua atividade.

8. A aplicação do critério da divisibilidade do valor da despesa tem o objetivo de identificar o valor exato que o prestador do serviço gasta com certa despesa na realização de determinada prestação de serviço a um tomador específico. Se o prestador não puder identificar o valor exato da despesa cujo custo foi obrigado a antecipar para prestar o serviço da forma como contratada por um tomador específico, também não poderá exigir desse tomador o pagamento de determinada quantia a título de reembolso exclusivo daquela despesa.

8.1. Para estabelecer que uma despesa relacionada à determinada prestação de serviço é custeada por reembolso pago pelo seu tomador e que esse valor não deve compor a base de cálculo do ISS incidente sobre aquela prestação, não basta que essa despesa seja identificada como não essencial para a execução daquele tipo de serviço: também é necessário que seja possível a identificação do valor exato dessa despesa para que o pagamento desse valor possa ser exigido pelo prestador do seu tomador.

9. O critério da prescindibilidade da despesa para a execução de determinado tipo de serviço permite identificar uma despesa como decorrente de alguma particularidade que o prestador é obrigado a acrescentar na prestação do serviço para certo tomador, em razão das exigências que ele lhe impôs no momento de sua contratação. Por ser prescindível, trata-se de despesa que não será verificada em toda e qualquer prestação desse serviço que for executada pelo prestador, mas apenas em prestações específicas. Caracteriza-se, então, como uma despesa que deve ser custeada por meio de reembolso.

9.1. Diferentemente, se determinada despesa for imprescindível para que o prestador possa executar o serviço em benefício de todo e qualquer tomador que o contratar, essa despesa certamente estará relacionada à própria natureza desse tipo de serviço, à execução da atividade-fim executada por esse prestador. Como tal, essa despesa será caracterizada como uma despesa própria do prestador do serviço, que deve ser custeada com a receita auferida por ele com a prestação do seu serviço.

10. A conjugação desses três critérios permite afirmar que aqueles valores que forem recebidos pelo prestador do serviço do seu tomador que se destinem ao custeio de despesas ocorridas de forma específica na prestação de serviço realizada para esse tomador, que 
tenham um valor certo e que não sejam imprescindíveis para a realização daquele tipo de serviço de uma forma geral devem ser considerados como reembolso e, por consequência, não podem compor a base de cálculo do ISS.

10.1. Qualquer cobrança de ISS que se faça sobre esses valores recebidos pelo prestador de serviço a título de reembolso estará atingindo materialidade diversa daquela atribuída pela Constituição aos Municípios para a cobrança do ISS, o que tornará essa cobrança inconstitucional.

10.2. Caso a despesa analisada não se enquadre em um ou mais dos critérios propostos (especificidade, divisibilidade ou prescindibilidade da despesa), deverá ser custeada com parte da receita recebida pelo prestador como contraprestação pelo serviço realizado. Por conta disso, esses valores devem ser considerados na apuração da base de cálculo do ISS incidente sobre essa prestação de serviço, pois constituem riqueza gerada pelo prestador e utilizadas para pagar as despesas próprias da prestação do serviço.

11. Também foram propostos critérios objetivos para diferenciar os valores recebidos a título de receita de serviço daqueles valores que apenas transitam temporariamente pelo caixa da empresa prestadora de serviços, que os encaminha para seus verdadeiros titulares. Trata-se, nesse último caso, de meros ingressos.

11.1. Por não remunerarem a atividade de prestação de serviço realizada pelo prestador, esses valores recebidos como meros ingressos não têm relação com a materialidade tributável pelo ISS e, por consequência, não devem compor a base de cálculo desse imposto municipal.

12. Os dois critérios cumulativos que foram propostos neste trabalho para diferenciar meros ingressos de receitas de prestação de serviço foram (i) o critério da titularidade do ingresso e (ii) o critério da definitividade da incorporação do valor ao patrimônio do prestador do serviço.

12.1. Caso os valores recebidos pelo prestador de serviços devam ser repassados em determinado prazo para terceira pessoa, que é a verdadeira titular desses valores, não há que se falar em qualquer definitividade desses valores no patrimônio do prestador de serviço, e sim em transitoriedade. Trata-se, nesse caso, de mero ingresso registrado pelo prestador, que é recebido por ele sem qualquer relação com a materialidade concretizada na prestação de determinado serviço. Por conta disso, esse valor não deve compor a base de cálculo do imposto incidente sobre aquela prestação. 
12.2. Por outro lado, a aplicação conjunta daqueles dois critérios também demonstrou que os valores recebidos do tomador que permanecem de forma definitiva com o prestador, integrando o seu patrimônio, por ser ele o seu titular, correspondem a ingressos que podem ser diferenciados em "receitas" e "reembolsos".

13. Também é necessário considerar os efeitos que têm os descontos concedidos sobre o preço do serviço estipulado inicialmente pelo prestador sobre a base de cálculo do Imposto sobre Serviços. Esses descontos são classificados pela doutrina e pela jurisprudência atuais em condicionados e incondicionados, a depender da existência ou não de uma condição que deve ser cumprida pelo tomador para que o desconto seja efetivamente concedido, classificação que também diferencia os seus efeitos tributários

13.1. No caso dos descontos incondicionados, o prestador, em qualquer hipótese, receberá o preço do serviço sem o valor do desconto, posto que o preço do serviço já foi alterado no momento da ocorrência do fato jurídico tributável por meio do ISS. Esse valor nunca será recebido efetivamente pelo prestador e não poderá, portanto, ser considerado como base de cálculo do ISS.

13.2. Diferentemente, quando os descontos são concedidos de forma condicionada, o serviço é prestado pelo valor inicialmente contratado e, posteriormente, em decorrência de convenções particulares estabelecidas entre prestador e tomador em relação à forma de pagamento desse serviço, o seu preço é modificado. Por isso, a apuração do valor do ISS devido deve considerar a materialidade efetivamente realizada pelo prestador do serviço e a riqueza gerada por ele com a concretização desse fato.

13.3. Assim como o inadimplemento total do preço do serviço pelo tomador não exclui o direito do Fisco de exigir o pagamento do ISS sobre o fato jurídico tributário concretizado, o fato de o prestador poder exigir do tomador o pagamento do preço total do serviço se ele não cumprir com a condição estabelecida para a concessão do desconto condicionado permite que esse valor seja incluído na base de cálculo do ISS incidente sobre essa prestação de serviço.

14. A ocorrência de uma mesma prestação de serviço no território de mais de um Município também causa problemas na definição da base de cálculo do ISS. Nesse caso, o critério material da regra-matriz de incidência do ISS é concretizado no território de mais de um Município, o que confere a todos eles a competência para tributar esse fato. 
14.1. Quando uma prestação de serviço compreender a realização de uma atividadefim no território de um Município e de outras atividades-meio imprescindíveis para aquela em outros Municípios diferentes, a definição da base de cálculo do ISS incidente sobre essa prestação deve considerar o preço cobrado pelo prestador para remunerar a realização da atividade-fim, ainda que, para a definição desse preço, também tenham sido consideradas despesas incorridas na execução daquelas atividades-meio. Nesse caso, a competência para a cobrança desse imposto cabe apenas ao Município onde foi realizada a atividade-fim.

14.2. Porém, quando a mesma atividade-fim é concretizada de forma concomitante em estabelecimentos localizados em territórios de Municípios distintos, todos os Municípios envolvidos na execução dessa prestação de serviço têm competência para tributá-la. Nessa situação, o conflito de competências decorre da existência de um único preço de serviço que remunera a prestação de serviço executada em todos aqueles estabelecimentos e que deverá ser rateado para a apuração da base de cálculo do ISS a ser cobrado por cada um daqueles Municípios, sem que haja critério para esse rateio previsto em lei complementar.

15. A omissão da legislação complementar nacional na prescrição de critérios para dirimir o tipo de conflito de competência que se verifica na apuração da base de cálculo do ISS incidente sobre prestações de serviços realizadas nos territórios de mais de um Município não autoriza os legisladores municipais a legislarem sobre essa matéria. Se fosse permitido, seria grande a probabilidade de que a prescrição de determinados critérios pela legislação de um Município levasse à invasão da competência tributária do outro Município, além da possível prescrição de múltiplas cobranças de ISS sobre a mesma parcela de receita decorrente da mesma prestação de serviço.

15.1. Diante das regras atualmente postas no ordenamento jurídico vigente, a utilização da equidade como instrumento de interpretação e de integração da legislação tributária é uma forma legal de se tentar resolver esse tipo de conflito.

15.2. Entende-se a equidade como instrumento de realização da justiça no caso concreto, a ser utilizado para resolver os conflitos decorrentes de situações concretas que não foram previstas em lei como hipóteses para a aplicação de uma consequência jurídica.

15.3. Em matéria tributária, a aplicação da equidade não pode se sobrepor à aplicação do princípio da legalidade tributária. Não é esse o caso em questão, pois, existindo lei própria em cada Município prevendo a incidência de ISS sobre prestações de serviço, faltará apenas a previsão da base de cálculo para completar essa incidência. 
15.4. A aplicação da equidade para solucionar esse tipo de conflito deve nortear a busca por critérios objetivos que estejam relacionados com a materialidade "prestar serviços de qualquer natureza" e que possam levar a um rateio do preço do serviço de tal forma que todos os Municípios envolvidos possam exercer a sua competência tributária, ao mesmo tempo em que a capacidade contributiva do prestador seja respeitada.

15.5. A eleição desse critério para o rateio da base de cálculo feito com o uso da equidade deve ser fundamentada em provas contundentes produzidas pelo sujeito que o utilizou na apuração do ISS devido (o contribuinte ou a autoridade administrativa). Essas provas devem ser capazes de demonstrar a intrínseca relação existente entre o critério eleito e a materialidade atingida por esse imposto.

15.6. Se a validade do crédito tributário de ISS constituído com base nesse critério de rateio for questionada, caberá à autoridade julgadora, seja em tribunal administrativo ou judicial, verificar se aquelas provas realmente demonstram a adequação do critério eleito. Caso não haja essa confirmação, essa autoridade deverá anular tal crédito tributário, pois não tem competência para revisar o lançamento tributário.

16. Conclui-se pela necessidade de que a atual legislação complementar que estipula normas gerais para a instituição e a cobrança do Imposto sobre Serviços seja alterada o quanto antes para que possa cumprir integralmente seu papel de dirimir conflitos de competência em matéria tributária, especialmente nos casos em que a materialidade tributável é concretizada no território de mais de um Município. Com a previsão de critérios objetivos para o rateio da receita de serviços a ser considerada como base de cálculo do ISS a ser cobrado nesses casos, essa legislação passaria a garantir que a tributação dessas prestações de serviço se daria de forma objetiva e isonômica. 


\section{REFERÊNCIAS}

ALVES, Anna Emilia Cordelli. A base de cálculo do ISS. In: TORRES, Heleno Taveira (org.). ISS na Lei Complementar n. 116/2003 e na Constituição. Barueri/SP: Manole, 2004, p. 174-189.

AMARO, Luciano. Direito tributário brasileiro. 9. ed. São Paulo: Saraiva, 2003.

ANDRADE, José Maria Arruda de. Interpretação da norma tributária. São Paulo: MP Editora, 2006.

Instalação e Montagem no Âmbito dos Contratos de Turn Key (Conflito de Competência entre ICMS e ISS). Revista Eletrônica de Direito Tributário da ABDF. Disponível em: <http://www.abdf.com.br/revista/artigo/287-instalacao-e-montagem-noambito-dos-contratos-de-turn-key-conflito-de-competencia-entre-icms-e-iss $>$. Acesso em: 07 jan 2015.

. Interpretação e Aplicação da Lei Tributária: da Consideração Econômica da Norma Tributária à Análise Econômica do Direito. In: MACHADO, Hugo de Brito (Coord.) Interpretação e aplicação da Lei Tributária. São Paulo: Dialética; Fortaleza: Instituto Cearense de Estudos Tributários - ICET, 2010, p. 182-206.

ARAÚJO, Clarice Von Oertzen. Semiótica do Direito. São Paulo: Quartier Latin, 2005.

ATALIBA, Geraldo. Hipótese de incidência tributária. $6^{\mathrm{a}}$ ed. $9^{\mathrm{a}}$ tiragem. São Paulo: Malheiros, 2008.

República e Constituição. 3 ed. atual. por Rosolea Miranda Folgosi. São Paulo: Malheiros Editores, 2011.

1971.

Lei Complementar na Constituição. São Paulo: Editora Revista dos Tribunais,

ÁVILA, Humberto. Sistema Constitucional Tributário. 5a ed. São Paulo: Saraiva, 2012.

BALEEIRO, Aliomar. Uma Introdução à Ciência das Finanças. 19 ed. revista e atualizada por Hugo de Brito Machado Segundo. Rio de Janeiro: Forense, 2015. 
BAPTISTA, Marcelo Caron. ISS: do texto à norma. São Paulo: Quartier Latin, 2005.

BARRETO, Aires F. Base de cálculo, alíquota e princípios constitucionais. São Paulo: Revista dos Tribunais, 1986.

Curso de Direito Tributário Municipal. 2 ed. São Paulo: Saraiva, 2012.

ISS na Constituição e na Lei. 3 ed. São Paulo: Dialética, 2009.

ISS na Constituição - Sociedades de Trabalho. Tributação Mitigada, como Exigência dos Princípios da Igualdade e da Capacidade Contributiva. Revista Dialética de Direito Tributário. n. 222. São Paulo: Dialética, março/2014, p. 7-35.

BARRETO, Paulo Ayres. Ampliação das Hipóteses de Retenção do ISS na Fonte. Limites Normativos. In: ROCHA, Valdir de Oliveira (Coord). Grandes Questões Atuais do Direito Tributário. $16^{\circ}$ vol. São Paulo: Dialética, 2012, p. 266-278.

. Contribuições: Regime Jurídico, Destinação e Controle. 2 ed. São Paulo: Noeses, 2011.

Elisão Tributária - Limites Normativos. 2008. 288 f. Tese de Livre Docência. Faculdade de Direito da Universidade de São Paulo, São Paulo, 2008.

BARRETO, Simone Rodrigues Costa. Mutação do Conceito Constitucional de Mercadoria. São Paulo: Noeses, 2015.

BATISTA, Luiz Rogerio Sawaya. Reembolso de "Despesas" e o ISS. In: DACOMO, Natalia de Nardi; MACEDO, Alberto (Coord.). ISS pelos Conselheiros Julgadores. São Paulo: Quartier Latin, 2012, p. 234-249.

BECKER, Alfredo Augusto. Teoria Geral do Direito Tributário. $4^{\text {a }}$ ed. São Paulo: Noeses, 2007.

BORGES, José Souto Maior. Aspectos fundamentais da Competência Municipal para instituir o ISS (do Decreto-lei n. 406/68 à LC n. 116/2003) (à memória de Geraldo Ataliba). In: TORRES, Heleno Taveira (Org.). ISS na Lei Complementar n. 116/2003 e na Constituição. Barueri/SP: Manole, 2004, p. 3-51. 
Obrigação Tributária (uma introdução metodológica). 2 ed. São Paulo: Malheiros Editores, 1999.

Teoria Geral da Isenção Tributária. $3^{\mathrm{a}}$ ed. rev. e atual. São Paulo: Malheiros Editores, 2007.

BRASIL. Constituição (1988). Constituição da República Federativa do Brasil. Brasília, DF: Senado, 1988.

Decreto-Lei $n^{0}$ 5.452, de $1^{\circ}$ de maio de 1943. Consolidação das Leis Trabalhistas. Aprova a Consolidação das Leis do Trabalho. Disponível em: <http://www.planalto.gov.br/ccivil_03/decreto-lei/Del5452.htm>.

Decreto-Lei $\mathrm{n}^{\circ}$ 57, de 18 de novembro de 1966. Altera dispositivos sobre lançamento e cobrança do Imposto sobre a Propriedade Territorial Rural, institui normas sobre arrecadação da Dívida Ativa correspondente, e dá outras providências. Disponível em: <http://www.planalto.gov.br/ccivil_03/decreto-lei/Del0057.htm>.

Decreto-Lei 406, de 31 de dezembro de 1968. Estabelece normas gerais de direito financeiro, aplicáveis aos impostos sobre operações relativas à circulação de mercadorias e sobre serviços de qualquer natureza, e dá outras providências. Disponível em: <http://www.planalto.gov.br/ccivil_03/decreto-lei/Del0406.htm>.

Lei $\mathbf{n}^{0}$ 3.071, de $\mathbf{1}^{\mathbf{0}}$ de janeiro de 1916. Disponível em: <http://www.planalto.gov.br/ccivil_03/leis/L3071.htm>.

Lei $n^{0}$ 5.172, de 25 de outubro de 1966. Código Tributário Nacional. Dispõe sobre o Sistema Tributário Nacional e institui normas gerais de direito tributário aplicáveis à União, Estados e Municípios. Disponível em: <http://www.planalto.gov.br/ccivil_03/Leis/L5172.htm>.

Lei $n^{0}$ 5.764, de 16 de dezembro de 1971. Define a Política Nacional de Cooperativismo, institui o regime jurídico das sociedades cooperativas, e dá outras providências. Disponível em: <http://www.planalto.gov.br/ccivil_03/LEIS/L5764.htm>.

Lei no 10.406, de 10 de janeiro de 2002. Código Civil Brasileiro. Disponível em: <http://www.planalto.gov.br/ccivil_03/leis/2002/L10406.htm>. 
Lei Complementar $n^{0}$ 63, de 11 de janeiro de 1990. Dispõe sobre critérios e prazos de crédito das parcelas do produto da arrecadação de impostos de competência dos Estados e de transferências por estes recebidos, pertencentes aos Municípios, e dá outras providências. Disponível em: <http://www.planalto.gov.br/ccivil_03/leis/LCP/Lcp63.htm>.

Lei Complementar $n^{\circ}$ 65, de 15 de abril de 1991. Define, na forma da alínea a do inciso X do art. 155 da Constituição, os produtos semi-elaborados que podem ser tributados pelos Estados e Distrito Federal, quando de sua exportação para o exterior. Disponível em: <http://www.planalto.gov.br/ccivil_03/leis/LCP/Lcp65.htm>.

. Lei Complementar no 87, de 13 de setembro de 1996 (Lei Kandir). Dispõe sobre o imposto dos Estados e do Distrito Federal sobre operações relativas à circulação de mercadorias e sobre prestações de serviços de transporte interestadual e intermunicipal e de comunicação, e dá outras providências. Disponível em: <http://www.planalto.gov.br/ccivil_03/leis/LCP/Lcp87.htm>.

Lei Complementar n. ${ }^{\circ}$ 116, de 31 de julho de 2003. Dispõe sobre o Imposto Sobre Serviços de Qualquer Natureza, de competência dos Municípios e do Distrito Federal, e dá outras providências. Disponível em: <http://www.planalto.gov.br/ccivil_03/leis/LCP/Lcp116.htm>.

Lei Complementar n. ${ }^{\circ}$ 116, de 31 de julho de 2003. Mensagem de Veto n. ${ }^{\circ} 362$, de 31 de julho de 2003. Disponível em: <http://www.planalto.gov.br/ccivil_03/leis/Mensagem_Veto/2003/Mv362-03.htm>. Acesso em: $31 \mathrm{dez} 2015$.

Lei Complementar $n^{0}$ 118, de 9 de fevereiro de 2005. Altera e acrescenta dispositivos à Lei n⿳ํㅡㄴ 5.172, de 25 de outubro de 1966 - Código Tributário Nacional, e dispõe sobre a interpretação do inciso I do art. 168 da mesma Lei. Disponível em: <http://www.planalto.gov.br/ccivil_03/leis/LCP/Lcp118.htm>.

Lei Complementar $n^{0}$ 123, de 14 de dezembro de 2006. Institui o Estatuto Nacional da Microempresa e da Empresa de Pequeno Porte; altera dispositivos das Leis $\mathrm{n}^{0}$ 8.212 e 8.213, ambas de 24 de julho de 1991, da Consolidação das Leis do Trabalho - CLT, aprovada pelo Decreto-Lei no 5.452, de 1을 de maio de 1943, da Lei no 10.189, de 14 de fevereiro de 2001, da Lei Complementar no 63, de 11 de janeiro de 1990; e revoga as Leis no 9.317, de 5 de dezembro de 1996, e 9.841, de 5 de outubro de 1999. Disponível em: <http://www.planalto.gov.br/ccivil_03/leis/LCP/Lcp123.htm>.

Projeto de Lei do Senado n. ${ }^{\text {3 386, de }} 2012$ (complementar). Senado Federal. Disponível em: 〈http://www25.senado.leg.br/web/atividade/materias/-/materia/108390>. Acesso em: 05 jan. 2016. 
CARRAZZA, Elisabeth Nazar. O Imposto sobre Serviços na Constituição. Dissertação de Mestrado. Faculdade de Direito da PUC/SP. São Paulo, 1976.

CARRAZZA, Roque Antonio. Curso de Direito Constitucional Tributário. 30 ed. rev., ampl. e atual. até a Emenda Constitucional n. 84/2014. São Paulo: Malheiros Editores, 2015.

ICMS. 13 ed. rev. e ampl. até a EC 56/2007, e de acordo com a LC 87/1996 com sua ulteriores modificações. São Paulo: Malheiros Editores, 2009.

Reflexões sobre a Obrigação Tributária. São Paulo: Noeses, 2010.

CARVALHO, Aurora Tomazini de. Curso de Teoria Geral do Direito: O Construtivismo Lógico-Semântico. 2 ed. São Paulo: Noeses, 2010.

CARVAlHO, Paulo de Barros. Curso de Direito Tributário. 26 ed. São Paulo: Saraiva, 2014.

Derivação e Positivação no Direito Tributário. v.1. São Paulo: Noeses, 2011.

Direito tributário: fundamentos jurídicos da incidência. 8 ed. rev. São Paulo: Saraiva, 2010.

Direito tributário: linguagem e método. 5 ed. São Paulo: Noeses, 2013.

COÊLHO, Sacha Calmon Navarro. Curso de Direito Tributário Brasileiro. 9 ed. Rio de Janeiro: Forense, 2006.

COSTA, Alcides Jorge. Algumas notas sobre o imposto sobre serviços. Revista de Direito Tributário Atual. n. 29. São Paulo: 2013, p. 30-35.

Estudos sobre IPI, ICMS e ISS. São Paulo: Dialética, 2009.

COSTA, Regina Helena. Curso de Direito Tributário: Constituição e Código Tributário Nacional. 5 ed. São Paulo: Saraiva, 2015.

Princípio da capacidade contributiva. 4. ed. atual., rev. e ampl. São Paulo: Malheiros Editores, 2012. 
DÁCOMO, Natália de Nardi. Hipótese de Incidência do ISS. São Paulo: Noeses, 2007.

ISS: Atividade-Fim X Atividade-Meio. In: MORAES PINTO, Sergio Luiz de; MACEDO, Alberto; ARAÚJO, Wilson José de (Coord.). Gestão Tributária Municipal e Tributos Municipais. Volume II - São Paulo: Quartier Latin, 2012, p. 389-404.

DERZI, Misabel de Abreu Machado. Direito Tributário, Direito Penal e Tipo. 2 ed. rev., atual. e ampl. São Paulo: Editora Revista dos Tribunais, 2007.

DICIONÁRIO de Latim-Português. 2a ed. Porto/Portugal: Porto Editora, 2001.

DINIZ, Maria Helena. Curso de direito civil brasileiro, volume 3: teoria geral das obrigações contratuais e extracontratuais. 31 ed. São Paulo: Saraiva, 2015.

ESTEVES, Maria do Rosário. O ISS das sociedades de profissionais: análise da LC $\mathrm{n}$. 116/2003. In: TORRES, Heleno Taveira (Org.). ISS na Lei Complementar n. 116/2003 e na Constituição. Barueri/SP: Manole, 2004, p. 432-451.

FALCÃO, Amilcar de Araújo. Fato Gerador da Obrigação Tributária. 7 ed. São Paulo: Noeses, 2013.

FERRAZ JUNIOR, Tercio Sampaio. Estudos de Filosofia do Direito. 3 ed. São Paulo: Atlas, 2009.

FLUSSER, Vilém. Língua e realidade. 2 ed. São Paulo: Annablume, 2004.

FURLAN, Valéria. IPTU. 2 ed. rev., atual. e ampl. São Paulo: Malheiros Editores, 2010.

GAMA, Tácio Lacerda. Competência Tributária: fundamentos para uma teoria da nulidade. 2 ed. rev. e ampl. São Paulo: Noeses, 2011.

GONÇALVES, Carlos Roberto. Direito civil brasileiro: contratos e atos unilaterais. 3 vol. 8 ed. São Paulo: Saraiva, 2011.

GONÇALVES, Gilberto Rodrigues. ISS na construção civil. São Paulo: Editora RBB, 1998. 
GRAU, Eros Roberto. O Direito Posto e o Direito Pressuposto. São Paulo: Malheiros Editores, 1998.

GRECO, Marco Aurélio. Solidariedade Social e Tributação. In: GRECO, Marco Aurélio; GODOI, Marciano Seabra de (Coord.) Solidariedade social e tributação. São Paulo: Dialética, 2005, p. 168-189.

ISS - construção civil - base de cálculo - exclusão dos materiais fornecidos pelo prestador - inconstitucionalidade. Revista Dialética de Direito Tributário. n. 72. São Paulo: Dialética, setembro/2001, p. 152-169.

GRUPENMACHER, Betina Treiger. A base de cálculo do ISS. In: TORRES, Heleno Taveira (Org.). ISS na Lei Complementar n. 116/2003 e na Constituição. Barueri/SP: Manole, 2004, p. 192-209.

Imposto sobre Serviços na Construção Civil. In: MORAES PINTO, Sergio Luiz de; MACEDO, Alberto; ARAÚJO, Wilson José de (Coord.). Gestão Tributária Municipal e Tributos Municipais. Volume II - São Paulo: Quartier Latin, 2012, p. 71-93.

HOFFMANN, Susy Gomes. A base de cálculo do ISS. In: TORRES, Heleno Taveira (Org.). ISS na Lei Complementar n. 116/2003 e na Constituição. Barueri/SP: Manole, 2004, p. 212-229.

HOUAISS, Antonio (1915-1999) e VILLAR, Mauro de Salles (1939-). Dicionário Houaiss da língua portuguesa. Rio de Janeiro: Objetiva, 2009.

HOVARTH, Estevão. Classificação dos Tributos. In: BARRETO, Aires F.; BOTALLO, Eduardo Domingos. (Coord.). Curso de iniciação em direito tributário. São Paulo: Dialética, 2004, p. 37-50.

JAKOBSON, Roman. Linguística e Comunicação. Cultrix: São Paulo, 2003.

JARDIM, Eduardo Marcial Ferreira. Dicionário Jurídico Tributário. 4 ed. São Paulo: Dialética, 2003.

JUSTEN FILHO, Marçal. O imposto sobre serviços na Constituição. São Paulo: Editora Revista dos Tribunais, 1985. 
LARENZ, Karl. Metodologia da Ciência do Direito. 3 ed. trad. José Lamego. Lisboa: Fundação Calouste Gulbenkian, 1997.

MACEDO, Alberto. ISS - O Conceito Econômico de Serviços já foi juridicizado há tempos também pelo Direito Privado. In: MACEDO, Alberto [et al.]. Direito Tributário e os Novos Horizontes do Processo. São Paulo: Noeses, 2015, p. 1-79.

O Conceito Constitucional de Serviços de Qualquer Natureza e as Recentes Decisões do Supremo Tribunal Federal. In: MORAES PINTO, Sergio Luiz de; MACEDO, Alberto; ARAÚJO, Wilson José de (Coord.). Gestão Tributária Municipal e Tributos Municipais. Volume II - São Paulo: Quartier Latin, 2012, p. 17-42.

MACHADO, Hugo de Brito. Curso de Direito Tributário. 20 ed. rev. atual. e ampl. São Paulo: Malheiros, 2002.

Lei Complementar Tributária. São Paulo: Malheiros Editores, 2010.

. Teoria Geral do Direito Tributário. São Paulo: Malheiros Editores, 2015.

MACHADO, Raquel Cavalcanti Ramos. Competência Tributária: entre a rigidez do sistema e a atualização interpretativa. São Paulo: Malheiros, 2014.

MARCHI, Eduardo C. Silveira. Guia de Metodologia Jurídica. 2 ed. São Paulo: Saraiva, 2009.

MARTINS, Sergio Pinto. Manual do Imposto sobre Serviços. 8 ed. atual., rev. e ampl. São Paulo: Atlas, 2010.

McNAUGHTON, Charles William. Elisão e Norma Antielisiva: Completabilidade e Sistema Tributário. São Paulo: Noeses, 2014.

MELO, Fábio Soares de. Cálculo do ISS: Alíquotas Máxima, Mínima e Tributação das Sociedades Profissionais. In: DACOMO, Natalia de Nardi; MACEDO, Alberto (Coord.). ISS pelos Conselheiros Julgadores. São Paulo: Quartier Latin, 2012, p. 159-177.

MELO, José Eduardo Soares de. ICMS: Teoria e Prática. 12 ed. São Paulo: Dialética, 2012. 
ISS - Aspectos Teóricos e Práticos. 5 ed. São Paulo: Dialética, 2008.

MENDES, Gilmar Ferreira; BRANCO, Paulo Gustavo Gonet. Curso de Direito Constitucional. 8 ed. rev. e atual. São Paulo: Saraiva, 2013.

MINATEL, José Antonio. Conteúdo do Conceito de Receita e Regime Jurídico para sua Tributação. São Paulo: MP Editora, 2005.

MORAES, Bernardo Ribeiro de. Doutrina e Prática das Taxas. 2 ed. São Paulo: Quartier Latin, 2007.

Doutrina e prática do Imposto sobre Serviços. 1 ed. 2 tir. São Paulo: Editora Revista dos Tribunais, 1978.

MOUSSALLEM, Tárek Moysés. Fontes do Direito Tributário. 2 ed. São Paulo: Noeses, 2006.

Notas sobre o ISS e a Subempreitada. In: SANTI, Eurico Marcos Diniz de (Coord.) Tributação e Desenvolvimento - homenagem ao Prof. Aires Barreto. São Paulo: Quartier Latin, 2011, p. 771-784.

; CAMPOS JR., Ricardo Álvares da Silva. A base de cálculo do ISS: o preço do serviço. In: TORRES, Heleno Taveira (Org.). ISS na Lei Complementar n. 116/2003 e na Constituição. Barueri/SP: Manole, 2004, p. 231-252.

NOGUEIRA, Ruy Barbosa. Curso de direito tributário. 15. ed. atual. São Paulo: Saraiva, 1999.

OLIVEIRA, Regis Fernandes de. HORVATH, Estevão. Manual de direito financeiro. 5 ed. rev. São Paulo: Editora Revista dos Tribunais, 2002.

PADOVEZE, Clóvis Luís; TAKAKURA JUNIOR, Franco Kaolu. Custo e Preços de Serviços: logística, hospitais, transporte, hotelaria, mão de obra, serviços em geral. São Paulo: Atlas, 2013.

PEREIRA FILHO, Luiz Alberto. Taxas e Preços. Curitiba: Juruá Editora, 2008. 
RAMIRES, Rogério. A Não Incidência do ISS Sobre o Reembolso nos Contratos de Rateio de Custos e Despesas. In: DACOMO, Natalia de Nardi; MACEDO, Alberto (Coord.). ISS pelos Conselheiros Julgadores. São Paulo: Quartier Latin, 2012, p. 503-516.

REZENDE, Condorcet; BRIGAGÃO, Gustavo; SOUZA, Alisson Carvalho de. A base de cálculo do ISS devido pelas sociedades profissionais. In: TORRES, Heleno Taveira (Org.). ISS na Lei Complementar n. 116/2003 e na Constituição. Barueri/SP: Manole, 2004, p. 398-429.

RIBEIRO, Osni Moura. Contabilidade de Custos. 2 ed. São Paulo: Saraiva, 2011.

RODRIGUES, Silvio. Direito civil: dos contratos e das declarações unilaterais da vontade. 3 vol. 19 ed. São Paulo: Saraiva, 1989-1990.

Direito civil: parte geral das obrigações. 2 vol. 32 ed. São Paulo: Saraiva, 2002.

ROLON NETO, Sebastião. Base de Cálculo do ISS na Construção Civil - Um Caso de (In)Segurança Jurídica. In: MORAES PINTO, Sergio Luiz de; MACEDO, Alberto; ARAÚJO, Wilson José de (Coord.). Gestão Tributária Municipal e Tributos Municipais. Volume II - São Paulo: Quartier Latin, 2012, p. 337-350.

SANTOS, Jefferson Eduardo Vasconcelos. Previsão Constitucional de Serviço. In: DACOMO, Natalia de Nardi; MACEDO, Alberto (Coord.). ISS pelos Conselheiros Julgadores. São Paulo: Quartier Latin, 2012, p. 188-199.

SCHOUERI, Luís Eduardo. Direito Tributário. São Paulo: Saraiva, 2011.

SILVA, De Plácido e. Vocabulário Jurídico. Nagib Slaibi Filho e Gláucia Carvalho (atual.). Rio de Janeiro, Editora Forense, 2009.

SILVA, José Afonso da. Aplicabilidade das Normas Constitucionais. 8 ed. São Paulo: Malheiros Editores, 2012.

SILVA, Sérgio André Rocha Gomes da. Da ilegalidade da inclusão, na base de cálculo do imposto sobre serviços, do montante das despesas incorridas para a prestação do serviço. Revista Dialética de Direito Tributário. n. 54. São Paulo: Dialética, março/2000, p. 100106.

TOMÉ, Fabiana Del Padre. A prova no Direito Tributário. 2 ed. São Paulo: Noeses, 2008. 
TORRES, Heleno Taveira. Direito Constitucional Tributário e Segurança Jurídica: Metódica da Segurança Jurídica do Sistema Constitucional Tributário. 2 ed. rev., atual. e ampl. São Paulo: Editora Revista dos Tribunais, 2012.

Direito tributário e direito privado: autonomia privada; simulação; elusão tributária. São Paulo: Editora Revista dos Tribunais, 2003.

VELlOSO, Andrei Pitten. Conceitos e Competências Tributárias. São Paulo: Dialética, 2005.

VENOSA, Silvio de Salvo. Direito civil: contratos em espécie. 3 vol. 4 ed. São Paulo: Atlas, 2004.

Direito civil: teoria geral das obrigações e teoria geral dos contratos. 2 vol. 3 ed. São Paulo: Atlas, 2003.

VILANOVA, Lourival. As estruturas lógicas e o sistema do direito positivo. 4 ed. São Paulo: Noeses, 2010.

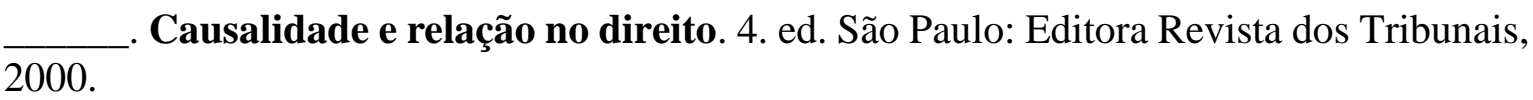

VITA, Jonathan Barros. O ISS e os Tratados Internacionais: Convergências Possíveis. In: DÁCOMO, Natalia De Nardi; MACEDO, Alberto (Coord.). ISS pelos Conselheiros Julgadores. São Paulo: Quartier Latin, 2012, p. 200-222. 